\title{
Associated Biologic Entity Type Code
}

National Cancer Institute

\section{Source}

National Cancer Institute. Associated Biologic Entity Type Code. NCI Thesaurus. Code C93734.

A coded value specifying the kind of associated biologic entity. 